Contract No. and Disclaimer:

This manuscript has been authored by Savannah River Nuclear Solutions, LLC under Contract No. DE-AC09-08SR22470 with the U.S. Department of Energy. The United States Government retains and the publisher, by accepting this article for publication, acknowledges that the United States Government retains a non-exclusive, paid-up, irrevocable, worldwide license to publish or reproduce the published form of this work, or allow others to do so, for United States Government purposes. 


\section{ANALYSIS OF THE PRESSURE TRANSIENT AND BURST PRESSURE FOR EXPOSURE OF THE 9975 PRIMARY CONTAINMENT VESSEL TO FIRE}

\author{
James E. Laurinat \\ Savannah River National Laboratory \\ Savannah River Site, Aiken, SC 29808 \\ Email: james.laurinat@srnl.doe.gov
}

Steve J. Hensel

Savannah River National Laboratory

Savannah River Site, Aiken, SC 29808

Email: steve.hensel@srnl.doe.gov

\begin{abstract}
Bare shipping package containment vessels can be utilized to stage plutonium oxide at the Savannah River Site. Pressurization and subsequent release could occur due to a hypothetical facility fire. Pressurization due to adsorbed moisture on the plutonium oxide and plastic packaging materials could result in rupture of the containment vessel. The containment vessel was evaluated to determine rupture pressure when subjected to the fire conditions. The rupture pressure is compared with pressures developed due to radiolytic gas generation.
\end{abstract}

\section{INTRODUCTION}

To support the calculation of potential dose consequences, an analysis of the pressure transient inside a 9975 primary containment vessel (PCV) exposed to a postulated $800^{\circ} \mathrm{C}$ fire was conducted to determine if the internal vessel pressure will exceed the burst pressure at the elevated container temperature. A schematic of the PCV is shown in Figure 1.

Within the PCV, plutonium oxide is packaged inside a slip lid can (SLC) within an inner can (IC). Plastic bags (usually polyethylene) are used with these cans for contamination control. The lid of the SLC is attached with tape. The PCV may also contain a hydrogen getter assembly consisting of a mixture of polyphenyl ether $\left(\mathrm{C}_{30} \mathrm{H}_{22} \mathrm{O}_{4}\right)$, and/or a Type $3 \mathrm{~A}$ zeolite molecular sieve and a honeycombed aluminum spacer. The getter material, plastic bags, and tape will decompose when heated by the fire.

\author{
Neal M. Askew \\ Savannah River National Laboratory \\ Savannah River Site, Aiken, SC 29808 \\ Email: neal.askew@srnl.doe.gov
}

\author{
Narendra K. Gupta \\ Savannah River National Laboratory (Retired) \\ Savannah River Site, Aiken, SC 29808 \\ Email: shashinick@gmail.com
}

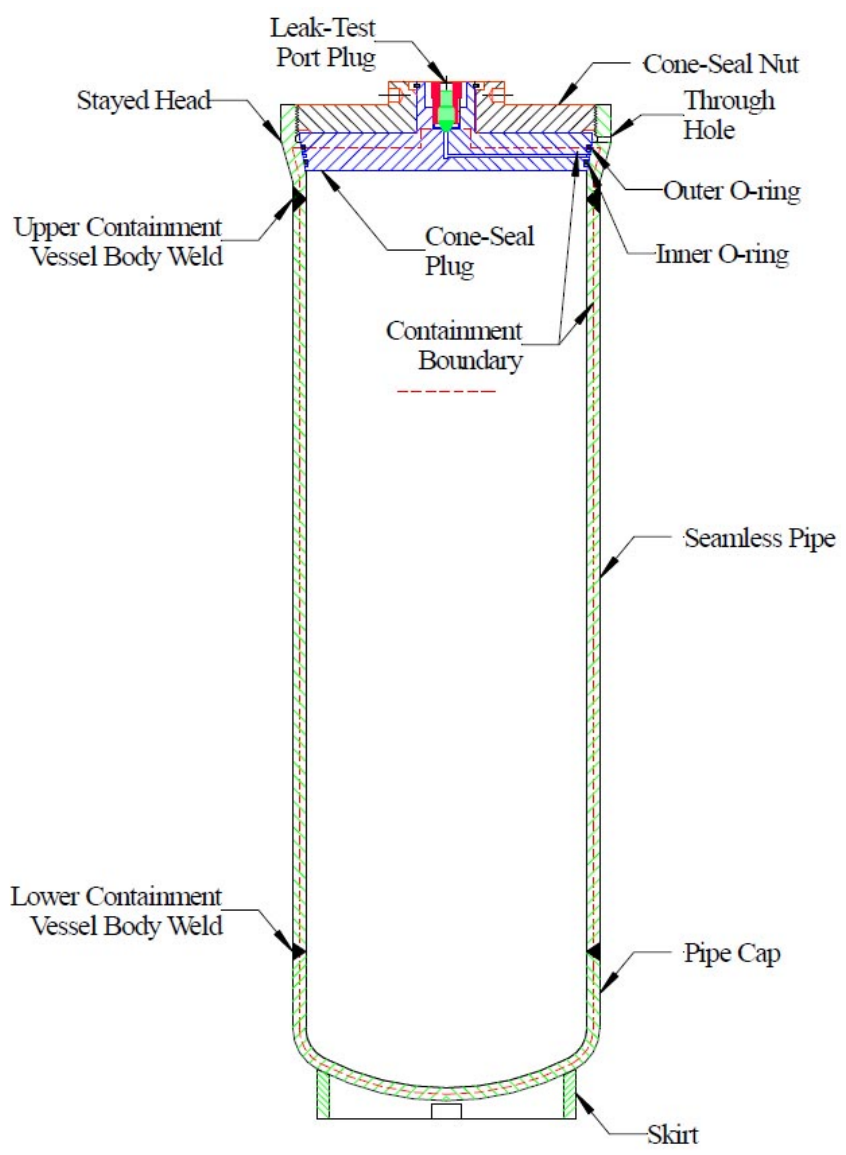

FIG 1. 9975 PRIMARY CONTAINMENT VESSEL (PCV)

The United States Government retains, and by accepting the article for publication, the publisher acknowledges that the Unites States Government retains, a non-exclusive, paid-up, irrevocable worldwide license to publish or reproduce the published form of this work, or allow others to do so, for United States Government purposes. This work was prepared under Federal Contract DE-AC09-08SR22470. 


\section{NOMENCLATURE}

$B_{1}$ factor for calculation of burst pressure from yield strength

$\mathrm{d}_{\mathrm{t}} \quad$ PCV lid thread root diameter

$\mathrm{F}_{1} \quad$ force acting on threads of PCV lid

$\mathrm{m} \quad$ radius to wall thickness ratio

$\mathrm{n}_{\mathrm{g}} \quad$ number of monolayers of adsorbed moisture

$\mathrm{P} \quad$ pressure inside $\mathrm{PCV}$

$\mathrm{P}_{\mathrm{b}} \quad$ PCV burst pressure

$\mathrm{R}$ gas law constant

$\mathrm{S}_{\mathrm{u}} \quad$ ultimate strength

$\mathrm{S}_{\mathrm{y}} \quad$ yield strength

$\mathrm{T}$ temperature, $\mathrm{K}$

$\mathrm{V}_{\mathrm{PCV}}$ gas space volume inside $\mathrm{PCV}$

$\beta \quad$ ratio of yield strength to ultimate strength

$\psi \quad$ factor for calculation of burst pressure from yield strength

\section{PRESSURIZATION CALCULATION}

The hypothetical fire is assumed to heat the PCV and its contents to $800{ }^{\circ} \mathrm{C}$. During exposure to the fire, the pressure inside the PCV will increase due to volumetric expansion of the gas initially present inside the PCV, evaporation of moisture adsorbed onto the plutonium oxide and/or the zeolite inside the $\mathrm{PCV}$, and gas generation from pyrolysis of the hydrogen getter material, plastic bagging material, other organic material inside the PCV, and the o-rings that seal the PCV. All organic materials except the getter material are treated conservatively as polyethylene in the pressure calculations. All gas pressures are calculated using the ideal gas law.

All water adsorbed on the plutonium dioxide or zeolite is assumed to evaporate into the vapor space during the postulated fire, adding to the moles of gas in the vapor space.

The amount of gas generated by pyrolysis is estimated from the mass of the getter material, the plastic bagging material, and the o-rings and knowledge of the getter material, bagging material, and o-ring chemistry. The PCV is sealed by inner and outer o-rings inserted between the cap and the base. It is assumed that the gases from the decomposition of the inner o-ring enter the PCV gas space and therefore pressurize the $\mathrm{PCV}$, while gases from the outer o-ring are vented to the secondary containment vessel (SCV); this arrangement is consistent with the assumption of no venting of the PCV. The specified o-ring material is either Viton ${ }^{\circledR}$ GLT or GLS. Viton ${ }^{\circledR}$ GLT is a polymer with the monomeric chemical formula $-\mathrm{CH}_{2}$ $\mathrm{CF}_{2}-\mathrm{CF}_{2}-\mathrm{CF}\left(\mathrm{OCF}_{3}\right)-\mathrm{CF}_{2}-\mathrm{CF}_{2}$ - and an approximate monomeric molecular mass of $330 \mathrm{~g} / \mathrm{mol}^{1}{ }^{1}$ Thermogravimetric analyses (TGA) of Viton ${ }^{\circledR}$ materials indicate that the thermal decomposition of Viton ${ }^{\circledR}$ generates nearly all gaseous products and leaves little solid residue. ${ }^{1}$ Accordingly, the analysis

\footnotetext{
${ }^{\circledR}$ Viton is a registered trademark of DuPont Performance Elastomers LLC of Wilmington, Delaware.
}

assumes that complete decomposition of the o-ring occurs at $800^{\circ} \mathrm{C}$. The number of moles of gas is estimated by assuming that the pyrolysis takes place in a reducing (oxygen-limited) atmosphere due to the presence of the plutonium oxide and that, consequently, the primary pyrolysis product gases per mole of monomer are one mole each of $\mathrm{C}_{2} \mathrm{H}_{2} \mathrm{~F}_{2}, \mathrm{CO}$, and $\mathrm{F}_{2}$ and two moles of $\mathrm{C}_{2} \mathrm{~F}_{4}$. Under this assumption, the pyrolysis of Viton ${ }^{\circledR}$ GLT would generate five moles of gas per mole of monomer.

The bagging material is polyethylene, which is a polymer with the monomeric formula $-\mathrm{C}_{2} \mathrm{H}_{4}$ - and an approximate molecular mass of $28 \mathrm{~g} / \mathrm{mol}^{2}{ }^{2}$ The decomposition kinetics for polyethylene are nearly identical to those for Viton ${ }^{\circledR}$, i.e., polyethylene decomposes nearly completely between $475^{\circ} \mathrm{C}$ and $525{ }^{\circ} \mathrm{C}$ when heated at $40^{\circ} \mathrm{C} / \mathrm{min} .^{3}$ It is assumed that the pyrolysis of polyethylene under the reducing atmosphere present in the PCV generates $\mathrm{C}_{2} \mathrm{H}_{4}$ gas at a rate of one mole per mole of monomer. Measured gas compositions for the pyrolysis of polyethylene confirm that $\mathrm{C}_{2} \mathrm{H}_{4}$ (ethylene) is one of the principal gas species generated by thermal decomposition in the absence of oxidizing gases. ${ }^{4}$ Moreover, an assumption that the pyrolysis gas is comprised of $\mathrm{C}_{2} \mathrm{H}_{4}$ provides a close bound to the number of moles of gas generated per unit mass of polyethylene. The PCV gas space is calculated using the ideal gas law:

$$
\mathrm{P}=\frac{\mathrm{n}_{\text {gas }} \mathrm{RT}}{\mathrm{V}_{\mathrm{PCV}}}
$$

The total moles of gas, $\mathrm{n}_{\text {gas }}$, is the sum of the moles of gas initially present, the moles of adsorbed water and the moles of degradation products from the thermally decomposed polymers.

The ideal gas law does not include the compressibility correction, which, at high temperatures and pressures, slightly reduces the volume a gas occupies at a given pressure. The compressibility factor also decreases the pressure for a given temperature and a fixed volume, so its omission in this analysis is conservative.

The pressurization due to moisture evaporation and material decomposition is inversely proportional to the volume of the gas space inside the PCV. The gas space is computed by subtracting the volumes of the Hanford Can and SLC walls, the plastic, the plutonium oxide, and the adsorbed moisture from the interior volume of the PCV. For packaging of product material from HB-Line, the plutonium oxide volume is based on a pycnometric density of $9.5 \mathrm{~g} / \mathrm{cm}^{3}$, measured for pure $\mathrm{PuO}_{2}$ calcined at $600{ }^{\circ} \mathrm{C} .^{5}$ This density represents a limiting density for low temperature calcination of plutonium oxalate and conservatively bounds the value recommended by the DOE Standard 3013, which is $90 \%$ of the crystalline density of $\mathrm{PuO}_{2}{ }^{6}$ The crystalline density of $\mathrm{PuO}_{2}$ is $11.46 \mathrm{~g} / \mathrm{cm}^{3}{ }^{7}$ No specific allowance is made for any volume occupied by salts or other impurities contained in HB-Line oxide. The total available gas space in the PCV for HB-Line oxide, subtracting all components including the hydrogen getter, is $4191 \mathrm{~cm}^{3}$. For 
packaging of material from K-Area or other sources, the oxide volume is based on an assumed limiting pycnometric density of $4.8 \mathrm{~g} / \mathrm{cm}^{3}$. This density accounts for the presence of salts and other impurities. The available gas space for material from KArea or other sources is $4005 \mathrm{~cm}^{3}$. Table 1 summarizes the calculation of the available gas space inside the PCV containers.

\section{TABLE 1. VOLUMES AND GAS SPACES INSIDE PRIMARY CONTAINMENT VESSEL (PCV)}

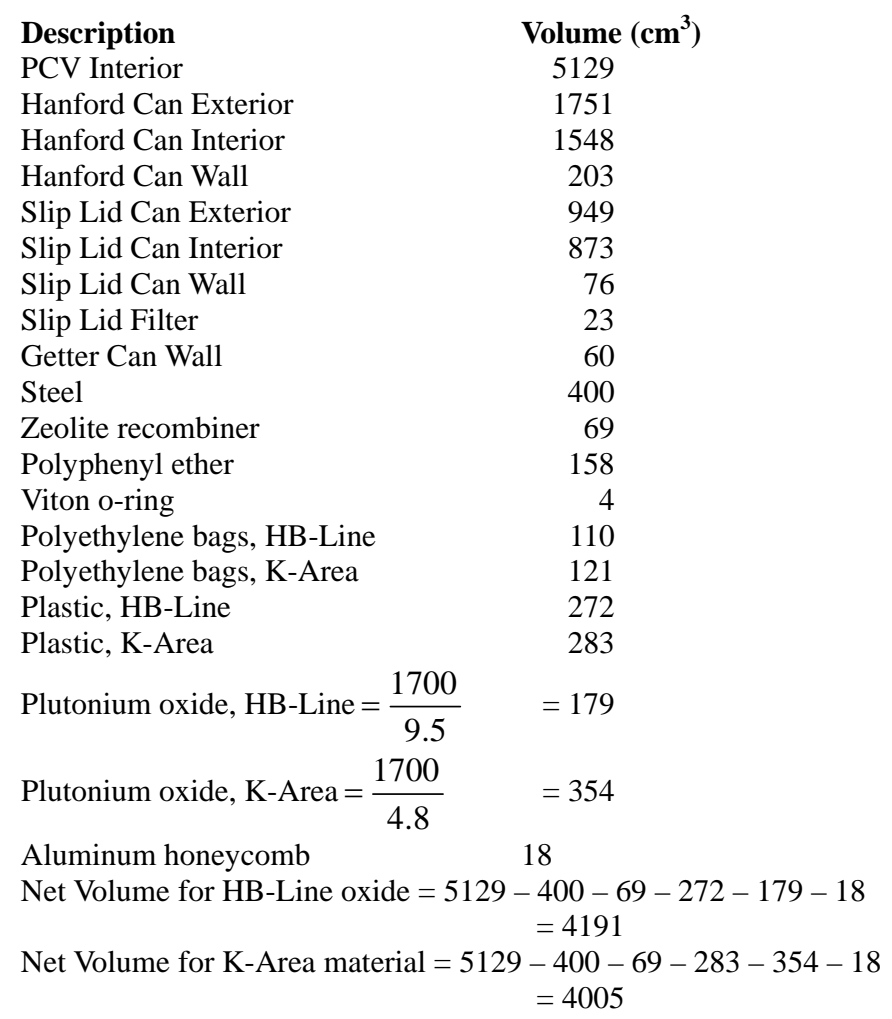

Note 1: Moisture is subtracted from the Net Volume as mass of adsorbed water divided by density at $1.0 \mathrm{~g} / \mathrm{cm}^{3}$.

Note 2 . The bag mass for the HB-Line packaging is conservatively set at $100 \mathrm{~g}$ to calculate the displacement volume. A mass of $65 \mathrm{~g}$ is used in the calculation of the pyrolytic gas generation.

Note 3: The steel volume in the Slip Lid Can, Hanford Can, and Getter Can is rounded up approximately $10 \%$ to account for deviations from nominal specified dimensions and approximations made in the calculation of the wall volumes

Note 4: The volume of the Hanford can bounds the volume of the FBLine can.

\section{STRUCTURAL ANALYSIS}

The analysis calculates the failure pressure for the primary containment vessel (PCV) used in the nuclear material package 9975. The PCV is fabricated to ASME Section III, Subsection NB code. ${ }^{8}$ The PCV base is a 5 -inch Sch. 40 seamless pipe fabricated from stainless steel Type 304L. ASME code does not permit Type 304L for pressure components beyond $1000^{\circ} \mathrm{F}$. ASME code permits Type 304 for high temperature application and its material strength properties, yield stress $\left(\mathrm{S}_{\mathrm{y}}\right)$ and ultimate stress $\left(\mathrm{S}_{\mathrm{u}}\right)$, are given in the ASME code, Subsection $\mathrm{NH}$ up to $1500{ }^{\circ} \mathrm{F}^{8}$ Some code guidance is used from the SS304 properties to derive SS304L properties beyond $1000^{\circ} \mathrm{F}$.

High temperature exposure of the PCV is limited to one hour. For this short time, thermal creep is not important. In addition, the fire loading is a one-time event and, therefore, no thermal fatigue consideration is given in the evaluation. The burst pressure evaluation is based on simplified formulation, PCV burst pressure data, and guidance from the ASME Code. No attempt is made to meet all the Code requirements.

Type 304L strength properties are taken from the ASME code. ${ }^{8}$ The code gives minimum strength values for Type 304L up to $1000{ }^{\circ} \mathrm{F}$ only. A comparison of SS304 and SS304L minimum yield strengths up to $1000^{\circ} \mathrm{F}$ shows that the reduction is $48.3 \%$ and $46.8 \%$, respectively. Therefore, the reduction in strength values for $304 \mathrm{~L}$ at $1500{ }^{\circ} \mathrm{F}$ is assumed to be same as Type 304. In addition, the reduction in yield strength for the SS304 between $1000{ }^{\circ} \mathrm{F}$ and the $1500{ }^{\circ} \mathrm{F}$ is fairly linear. The minimum properties of SS304L are given in Table 3 and are presented here for comparison only with the average or typical properties.

TABLE 3. MINIMUM STRENGTH PROPERTIES

$\begin{array}{lccccc}\text { Temp }\left({ }^{\circ} \mathbf{F}\right) & \mathbf{S}_{\mathbf{u}}(\mathbf{k s i}) & \mathbf{S}_{\mathbf{y}}(\mathbf{k s i}) & \mathbf{T e m p}\left({ }^{\circ} \mathbf{F}\right) & \mathbf{S}_{\mathbf{u}}(\mathbf{k s i}) & \mathbf{S}_{\mathbf{y}}(\mathbf{k s i}) \\ 100 & 70.0 & 25.0 & 700 & 56.4 & 15.0 \\ 200 & 66.1 & 21.4 & 800 & 55.4 & 14.5 \\ 300 & 61.2 & 19.2 & 900 & 54.6 & 14.0 \\ 400 & 58.4 & 17.5 & 1000 & 52.3 & 13.3 \\ 500 & 57.5 & 16.4 & 1472 & 21.08 & \mathbf{8 . 0 6} \\ 600 & 56.9 & 15.5 & 1500 & 19.23 & 7.75\end{array}$

As pointed out before, code does not permit the use of Type 304L for code certified vessels operating at temperatures above $1000^{\circ} \mathrm{F}$. The material does retain considerable strength and the industry does permit Type 304L for continuous usage up to $1600{ }^{\circ} \mathrm{F}^{9} \quad$ Average or typical strength properties are obtained from the industry literature. ${ }^{10}$ Average properties are given in Table 4. The numbers in red are interpolated for the ultimate strength while the value for yield strength is linearly extrapolated from $1200{ }^{\circ} \mathrm{F}$ and $1400{ }^{\circ} \mathrm{F}$ values. Since the material SS304L retains considerable strength up to $1600{ }^{\circ} \mathrm{F}$, a small extrapolation to $1472^{\circ} \mathrm{F}$ is acceptable.

TABLE 4. AVERAGE/TYPICAL STRENGTH PROPERTIES

$\begin{array}{lll}\text { Temp }\left({ }^{\circ} \mathbf{F}\right) & \mathbf{S}_{\mathbf{u}}(\mathbf{k s i}) & \mathbf{S}_{\mathbf{y}}(\mathbf{k s i}) \\ \text { Room } & 85.00 & 35.00 \\ 400 & 72.00 & 23.00 \\ 600 & 68.00 & 19.50 \\ 800 & 64.00 & 16.50 \\ 1000 & 56.00 & 14.00 \\ 1200 & 44.00 & 12.50 \\ 1400 & 29.00 & 11.00 \\ \mathbf{1 4 7 2} & 24.32 & \mathbf{1 0 . 4 6} \\ 1600 & 16.00 & \text { Not Available }\end{array}$


The intent of this evaluation is to calculate the allowable pressure for the PCV during fire. The method relies on the use of PCV test data to verify the accuracy of the methodology. Since the accuracy test uses the typical strength properties rather than minimum properties, the results are typical collapse pressures. A safety margin is applied using the code guidance to arrive at the final result. A schematic of the PCV with its components is shown in Fig. 1. The PCV failure scenarios are:

- Vessel shell bursting

- Cone seal nut failure

- Cone seal nut thread failure

The PCV was tested at room temperature to assess its burst pressure in the design and certification of the package 9975. The burst pressure was 7560 psig at room temperature. During testing the failure occurred on its shell longitudinally. The seal nut and the threads did not fail. It is assumed that even at high temperatures, the failure mode will be the same since it is a one-time thermal loading. The evaluation presented here is based on text book formulas that are regarded good for preliminary design. The formula is tested for accuracy for the PCV burst pressure observed at room temperature and is then used to calculate the burst pressure at $1472{ }^{\circ} \mathrm{F}\left(800^{\circ} \mathrm{C}\right)$. The cone seal nut did not fail in any tests due to its large thickness. The pressure load is transmitted to the seal nut via cone seal plug and does not result in any bending loads on the cone seal nut. Therefore, the pressure load is essentially transmitted as a shear load to the seal nut threads. Consequently, only threads are analyzed for shear failure.

The evaluation for shell bursting relies on the burst pressure (collapse load) of the PCV; no detailed plastic analysis is performed to meet the ASME Code requirements. Nonmandatory Appendix F (Section F-1331.1(c)(2)) of the Code ${ }^{8}$ gives guidance when using the collapse load for evaluation. Appendix $\mathrm{F}$ requires that the calculated collapse load shall be multiplied by a factor 0.90 to calculate the allowable load. The calculation steps are:

1. Calculate the collapse load at $1472^{\circ} \mathrm{F}$,

2. Calculate the allowable load by multiplying results from Step 1 by 0.9 .

The PCV was hydro tested until failure occurred. Figure 1 shows a failed specimen and an intact sample. The failure is longitudinal and is caused by higher hoop stresses.

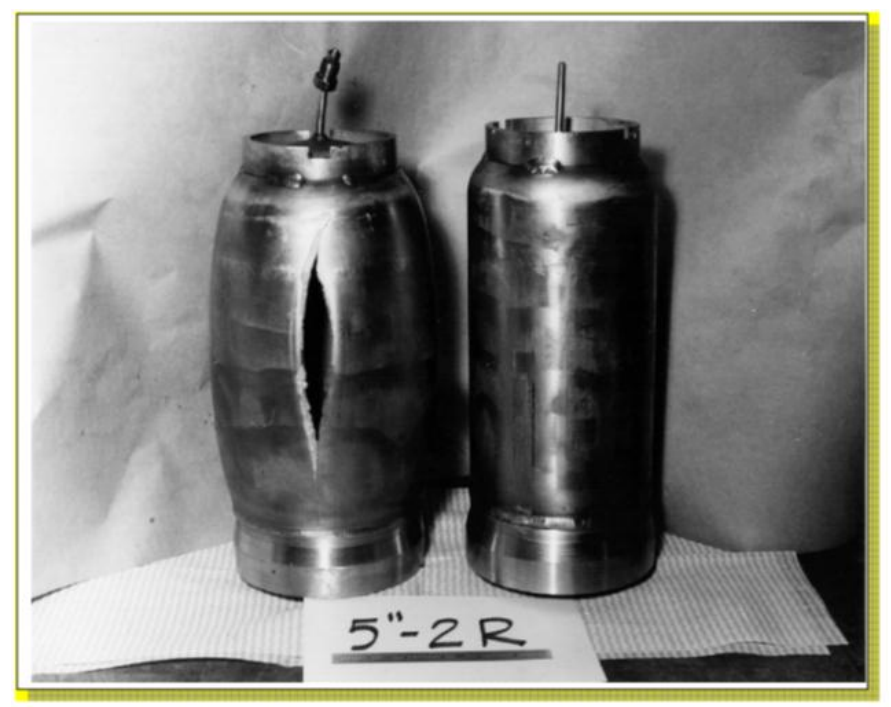

FIG 3. PCV (INVERTED) AFTER AND BEFORE THE BURST TEST

The burst pressure is calculated using the thick shell assumption: ${ }^{11}$

$$
\mathrm{P}_{\mathrm{b}}=\mathrm{S}_{\mathrm{y}} \psi \mathrm{B}_{1}
$$

The factors $\psi$ and $B_{1}$ are given in Figures 35.9 and 35.10 of Reference 11 . The factor $B_{1}$ depends upon the strength ratio $\beta$, where $\beta=\frac{S_{y}}{S_{u}}$ is the ultimate strength. The material properties are calculated at the operating temperature. The formula for the bust pressure is tested for the observed failure pressure of the PCV at room temperature. At the room temperature, the average strength properties for $304 \mathrm{~L}$ are taken from the AK Steel catalog: ${ }^{10} \mathrm{~S}_{\mathrm{y}}=35000 \mathrm{psi}, \mathrm{S}_{\mathrm{u}}=85000 \mathrm{psi}$.

This gives $\beta=0.412$. Using linear extrapolation from Figure 35.10 of Reference $10, B_{1}$ is found to be 2.214. Figure 35.9 of Reference 11 gives the geometry factor $\psi=0.1$ for $\mathrm{m}=10.28$, where $m$ is the radius to thickness ratio. Equation 1 then gives the burst pressure $\mathrm{P}_{\mathrm{b}}$. The mean radius-to-thickness $(\mathrm{R} / \mathrm{T})$ ratio of 10.28 of the PCV shell is at the upper end $(\mathrm{R} / \mathrm{T}=10)$ of the thick shell formula, so the application of equation 2 is assumed to be acceptable. At room temperature $\mathrm{P}_{\mathrm{b}}=35000 \mathrm{x}$ $0.1 \times 2.214=7749$ psig.

If a factor of 0.9 , as stated in the beginning of this section, is used to the above calculated burst pressure, we get a value of 6974 psig. This estimate is less than the burst pressure of 7560 psig found in the PCV test. This accuracy test gives confidence that the simple formula can be used to calculate the burst pressure at higher temperatures.

At a PCV temperature of $1472{ }^{\circ} \mathrm{F}\left(800{ }^{\circ} \mathrm{C}\right)$, Table 4 gives $\mathrm{S}_{\mathrm{y}}=10460$ psi and $\mathrm{S}_{\mathrm{u}}=24320$ psi. This gives $\beta=0.430$. 
From Figure 35.10 of Reference $11, \beta=0.430$ is slightly less than the limiting value of $\beta$ (0.50), so extrapolation can be used to calculate $B_{1} \cdot B_{1}$ is found to be 2.16. For this value of $\mathrm{B}_{1}$, equation 1 is used to calculate the burst pressure at $1472{ }^{\circ} \mathrm{F}$ $\left(800^{\circ} \mathrm{C}\right)$. At $1472^{\circ} \mathrm{F}\left(800^{\circ} \mathrm{C}\right) \mathrm{P}_{\mathrm{b}}=10460 \times 0.1 \times 2.16=2259$ psig.

Using the guidance from Appendix F Section 1331.1(C)(2) the static load at $1472{ }^{\circ} \mathrm{F}$ is $2259 \times 0.90=2033$ psig.

The seal nut does not experience any bending loading and sees only compressive loading from the PCV cone seal plug and therefore will not fail. Therefore, no further evaluation is performed.

There are 12 threads per inch in the seal nut. The thread root diameter $d_{t}$ is $5.063 \mathrm{in}$. The shear area of the threads at the roots is $=3.14 \times 5.063 \times 0.625=9.9412 \mathrm{in}^{2}$. The force acting on the threads, $F_{1}=$ Burst pressure $\mathrm{x}$ Seal Plug Area $=$ $2033 \times \pi \times(5.27)^{2} / 4=44300$ lbf. The shear stress at the roots of the threads $=44300 / 9.9412=4456$ psi. The shear ultimate stress is approximately $42 \%$ of the ultimate tensile strength. Therefore, the shear strength $=0.42 \times \mathrm{S}_{\mathrm{u}}=10214$ psi. Since the maximum shear stress at the root of the threads is only 4456 psi, the cone seal threads will not fail at the burst pressure.

\section{DISCUSSION OF RESULTS}

Separate parametric analyses were performed for material from K-Area and other sources (Case A) and for HB-Line plutonium oxide product (Case B). For K-Area material containing $1.5 \mathrm{~kg}$ of elemental plutonium (present as approximately $1.7 \mathrm{~kg}$ of oxide) and $110 \mathrm{~g}$ of polyethylene, Table 5 lists the calculated pressures at $800{ }^{\circ} \mathrm{C}$. Pressures are tabulated as functions of the moisture content inside the PCV in g. For a tightly sealed PCV (i.e. without taking credit for venting) pressures for exposure to the $800{ }^{\circ} \mathrm{C}$ fire would range from 3329 psig for $75 \mathrm{~g}$ of moisture to 4200 psig for $120 \mathrm{~g}$ of moisture.

Table 6 lists pressures at $800{ }^{\circ} \mathrm{C}$ for HB-Line oxide containing $1.5 \mathrm{~kg}$ of elemental plutonium (1.7 kg of plutonium oxide) and $65 \mathrm{~g}$ of polyethylene bagging. The maximum pressures for the HB-line oxide range from 2650 psig for $75 \mathrm{~g}$ of moisture to 3466 psig for $120 \mathrm{~g}$ of moisture.

\section{TABLE 5. EFFECT OF TOTAL MOISTURE LEVEL ON PCV PRESSURE FOR CASE A}

Note: Case $A$ is exposure of $1.7 \mathrm{~kg}$ of plutonium oxide with a pycnometric density of $4.8 \mathrm{~g} / \mathrm{cm}^{3}$ to a $800{ }^{\circ} \mathrm{C}$ fire without venting and with a hydrogen getter and $110 \mathrm{~g}$ of packaging plastic.

$\begin{array}{cc}\text { Mass } \mathbf{H}_{2} \mathbf{O}(\mathbf{g}) & \text { Pressure at } \mathbf{8 0 0}^{\circ} \mathbf{C} \\ 75 & 3329 \\ 100 & 3810 \\ 120 & 4200\end{array}$

\section{TABLE 6. EFFECT OF TOTAL MOISTURE LEVEL ON PCV PRESSURE FOR CASE B}

Note: Case $B$ is exposure of $1.7 \mathrm{~kg}$ of plutonium oxide with a pycnometric density of $9.5 \mathrm{~g} / \mathrm{cm}^{3}$ to a $800{ }^{\circ} \mathrm{C}$ fire without venting and with a hydrogen getter and $65 \mathrm{~g}$ of packaging plastic.

Mass $\mathbf{H}_{2} \mathbf{O}(\mathbf{g})$
75
100
120

The contributions of evaporation of moisture, decomposition of the plastic bags and the o-ring, and volumetric expansion of gases present in the PCV prior to heating can be compared. For example, of the total pressure increase of 3101 psig for Case B with a total moisture content of $100 \mathrm{~g}, 1758$ psig results from complete evaporation of the adsorbed moisture, 1560 psig is from the generation of gases from plastics decomposition, and 38 psig is due to volumetric expansion alone.

As the results in Tables 5 and 6 indicate, for a PCV containing $1.5 \mathrm{~kg}$ of elemental plutonium $(1.7 \mathrm{~kg}$ of plutonium oxide) with at least $75 \mathrm{~g}$ of moisture and and an appropriate amount of polyethylene bagging, the calculated pressures for fire exposure at $800{ }^{\circ} \mathrm{C}$ exceed the expected PCV burst pressure of 2033 psi at that temperature. Therefore, the PCV is expected to burst if exposed to an $800{ }^{\circ} \mathrm{C}$ fire.

Table 7 gives the calculated pressure at $800{ }^{\circ} \mathrm{C}$ without venting for a PCV charged with plutonium oxide, no more than $60 \mathrm{~g}, 90 \mathrm{~g}$ or $120 \mathrm{~g}$ of total plastic (the total plastic includes any Tyvek from the recombiner, tape, bag filters, o-ring or gasket on an inner can filter, etc.), and no hydrogen getter, but with a recombiner and fresh molecular sieve. The pressures in Table 7 are shown as a function of the oxide mass, plastic mass and percent adsorbed moisture. The pressure is a very nearly linear function of the oxide mass, plastic mass, or percent adsorbed moisture. A graph of the pressure versus any of these three independent variables will be very nearly linear and very slightly concave upwards. Therefore, a pressure calculated by linear interpolation between any two values in Table 6 will be accurate to within a few psig and slightly conservative. 
SRNL-STI-2014-00069

TABLE 7. PCV PRESSURE (PSIG) FOR EXPOSURE OF PLUTONIUM OXIDE WITH ADSORBED MOISTURE IN AN $800{ }^{\circ} \mathrm{C}$ FIRE WITHOUT VENTING

\begin{tabular}{|c|c|c|c|c|c|c|c|c|c|}
\hline \multirow{2}{*}{\multicolumn{3}{|c|}{ 0.75\% Moisture }} & \multicolumn{3}{|c|}{$1.0 \%$ Moisture } & \multicolumn{3}{|c|}{$1.25 \%$ Moisture } & \multirow[b]{2}{*}{120} \\
\hline & & & 120 & 60 & 90 & 120 & 60 & 90 & \\
\hline \multicolumn{10}{|c|}{ Grams Oxide } \\
\hline 2500 & 1178 & 1512 & 1850 & 1284 & 1619 & 1959 & 1391 & 1727 & 2068 \\
\hline 3000 & 1257 & 1595 & 1939 & 1386 & 1726 & 2072 & 1516 & 1858 & 2205 \\
\hline 3500 & 1337 & 1681 & 2030 & 1491 & 1836 & 2188 & 1644 & 1992 & 2345 \\
\hline 4000 & 1420 & 1770 & 2124 & 1598 & 1949 & 2307 & 1777 & 2130 & 2490 \\
\hline 4500 & 1506 & 1860 & 2221 & 1709 & 2066 & 2429 & 1913 & 2273 & 2639 \\
\hline 5000 & 1593 & 1954 & 2320 & 1822 & 2186 & 2555 & 2053 & 2419 & 2792 \\
\hline \multicolumn{3}{|c|}{ 1.5\% Moisture } & \multicolumn{3}{|c|}{ 1.75\% Moisture } & \multicolumn{2}{|c|}{$2.0 \%$ Moisture } & & \\
\hline Grams Plastic & 60 & 90 & 120 & 60 & 90 & 120 & 60 & 90 & 120 \\
\hline \multicolumn{9}{|c|}{ Grams Oxide } & \\
\hline 2500 & 1498 & 1835 & 2178 & 1605 & 1944 & 2288 & 1712 & 2052 & 2398 \\
\hline 3000 & 1646 & 1990 & 2338 & 1777 & 2122 & 2472 & 1908 & 2255 & 2607 \\
\hline 3500 & 1799 & 2148 & 2504 & 1954 & 2306 & 2663 & 2110 & 2463 & 2823 \\
\hline 4000 & 1956 & 2312 & 2674 & 2136 & 2495 & 2859 & 2317 & 2678 & 3045 \\
\hline 4500 & 2118 & 2481 & 2849 & 2324 & 2690 & 3061 & 2532 & 2900 & 3274 \\
\hline 5000 & 2285 & 2654 & 3030 & 2518 & 2891 & 3270 & 2753 & 3129 & 3511 \\
\hline
\end{tabular}

At $1.0 \%$ moisture and $60 \mathrm{~g}$ of plastic, the pressure in a fire is less than the burst pressure of the PCV. This allows the amount of plastic to be increased and still remain below the burst pressure in a fire. For $5.0 \mathrm{~kg}$ of plutonium oxide with no more than $1.0 \%$ moisture, the allowable total plastic can be increased to $77 \mathrm{~g}$ with a resulting pressure of $2027 \mathrm{psig}$. At $1.5 \%$ moisture, the total plastic can be increased to $66 \mathrm{~g}$ for the case of $4.0 \mathrm{~kg}$ of plutonium oxide with a resulting pressure of 2027 psig. If the moisture can be shown to be at or below $0.5 \%, 5.0 \mathrm{~kg}$ of plutonium oxide and a total plastic mass of 115 $\mathrm{g}$ would result in a pressure of 2026 psig.

\section{SUMMARY AND CONCLUSIONS}

The minimum expected burst pressure of the primary containment vessel (PCV) at $1472{ }^{\circ} \mathrm{F}\left(800{ }^{\circ} \mathrm{C}\right)$ is 2033 psig. The seal cone nut or its threads will not fail at the PCV burst pressure.

The pressurization of the PCV during exposure to an 800 ${ }^{\circ} \mathrm{C}$ fire has been calculated without taking credit for venting, which is anticipated as the o-ring would fail at elevated temperatures. The primary contributors to the increase in pressure inside the PCV during heating are evaporation of moisture adsorbed on the plutonium oxide contents and the zeolite in the getter assembly and generation of gases from decomposition of plastic bagging material and hydrogen getter material. Pressure transients have been evaluated for a PCV with $1.5 \mathrm{~kg}$ elemental plutonium (present as approximately 1.7 $\mathrm{kg}$ plutonium oxide), from 75 to $120 \mathrm{~g}$ adsorbed moisture, and an appropriate amount of polyethylene bagging material. The calculated pressures at $800{ }^{\circ} \mathrm{C}$ range from 2650 psig for $75 \mathrm{~g}$ total moisture to $3466 \mathrm{psig}$ for $120 \mathrm{~g}$ moisture. The corresponding pressures for material from K-Area or other sources are $3329 \mathrm{psig}$ for $75 \mathrm{~g}$ moisture and $65 \mathrm{~g}$ of polyethylene bagging and 4200 psig for $120 \mathrm{~g}$ moisture and 110 g of polyethylene. These pressures exceed the expected burst pressure at this temperature, so the PCV is expected to burst if exposed to an $800{ }^{\circ} \mathrm{C}$ fire.

For the additional case, the calculated pressure at $800{ }^{\circ} \mathrm{C}$ is reduced by limiting the amount of water present. A PCV charged with $5.0 \mathrm{~kg}$ of plutonium oxide with no more than $1 \%$ moisture and no more than 77 grams of plastic present has a calculated pressure at $800{ }^{\circ} \mathrm{C}$ of 2027 psig, which is below the burst pressure. For this case, the PCV is expected to survive a $800{ }^{\circ} \mathrm{C}$ fire. At $1.5 \%$ moisture the total plastic can be increased to $66 \mathrm{~g}$ for the case of $4.0 \mathrm{~kg}$ of Pu oxide resulting in $2027 \mathrm{psig}$. Table 7 presents other combinations of plutonium oxide loading, \% moisture, and grams of plastic that are also below the PCV burst pressure of 2033 psig.

It should be noted that the PCV o-ring is not rated for 800 ${ }^{\circ} \mathrm{C}$, thus leakage through the PCV threaded closure cannot be precluded. Any leakage would reduce the PCV internal pressure.

The PCV pressurization analysis is conservative due to two simplifications:

1. The PCV is assumed rigid as internal volume expansion due to deformation of the vessel has been neglected.

2. The heating of the water vapor and gases inside the PCV is assumed to identically follow the transient fire temperature curve. In reality, the water vapor and gas temperature would be somewhat lower as the thermal inertia and thermal resistance of the system have been neglected for this limited duration fire. 


\section{REFERENCES}

1. T. W. Giants, "Viton ${ }^{\circledR}$ GLT O-Ring Resilience Study," The Aerospace Corporation Report No. TR2001(1413)-4, U. S. Air Force Space and Missile Systems Center Report No. SMC-TR-02-25, March 15, 2001.

2. National Institute of Standards and Technology Chemical Webbook, (http://www.chemicalbook.com/ChemicalProductProp erty_EN_CB5128662.htm).

3. W. J. Sichina, "Characterizing Polymer Lifetimes Using TGA Decomposition Kinetics," PerkinElmer Instruments Report PETech-66.

4. C. Berreuco, J. Ceamanos, E. Esperanza, and J. F. Mastral, "Experimental Study of Co-Pyrolysis of Polyethylene/Sawdust Mixtures," Therm. Sci., 8(2), 65-80, 2004.

5. D. K. Veirs, "Gas Generation from Water Adsorbed onto Pure Plutonium Dioxide Powder," Mater. Res.
Soc. Symp. Proc. Vol. 893, Paper 0893-JJ07-03.1, 2006.

6. DOE-STD-3013-2012, Stabilization, Packaging, and Storage of Plutonium-Bearing Materials, March 2012.

7. CRC Handbook of Chemistry and Physics, $75^{\text {th }}$ ed., CRC Press, Boca Raton, Florida (1994), Chapter 4.

8. ASME B\&PV Code, Section II Part D and Section III, Division I, Subsection NH, 2010.

9. "Alloy Data, Carpenter Stainless Steel Type 304/304L,” CRS Holdings Inc., (www.veridiam.com/pdf/DataSheet304_304L.pdf).

10. Product Data Bulletin in 304/304L Stainless Steel, Table 2, AK Steel Corp, (www.aksteel.com/pdf/markets_products/stainless/aus tenitic/304_304L_Data_Bulletin.pdf).

11. A. Blake, Practical Stress Analysis in Engineering Design, $1^{\text {st }}$ ed., Marcell Dekker, Inc., New York (1982). 